OPEN ACCESS

Edited by:

Francesca Pesciarelli, University of Modena and Reggio

Emilia, Italy

Reviewed by:

Mary MacLean,

Defence Research and Development

Canada (DRDC), Canada

Ken Kihara

National Institute of Advanced Industrial Science and Technology (AIST), Japan

*Correspondence:

Xia Zhu

zhuxia_285459079@qq.com

Specialty section: This article was submitted to

Cognitive Science, a section of the journal Frontiers in Psychology

Received: 01 May 2020 Accepted: 22 June 2020

Published: 14 July 2020

Citation:

Li F, Liu Q, Lu H and Zhu X (2020) Attentional Blink in Pilots and lts Relationship With Flight Performance.

Front. Psychol. 11:1696. doi: 10.3389/fpsyg.2020.01696

\section{Attentional Blink in Pilots and Its Relationship With Flight Performance}

\author{
Fengzhan Li, Quanhui Liu, Huijie Lu and Xia Zhu* \\ Department of Military Medical Psychology, Air Force Medical University, Xi'an, China
}

Objective: In flight, military pilots need to monitor changes in the external environment and monitor the situation of the aircraft at the same time. Attentional blink (AB) reflects attentional blindness in time. Therefore, the present study investigated the $A B$ effect in military pilots and its relationship with flight performance.

Methods: Thirty male military pilots (44.23 \pm 4.07 years old) and 29 control participants (44.07 \pm 2.93 years old) underwent testing with the classic rapid serial visual presentation paradigm. The participants' accuracy in detecting a second target stimulus (T2/T1) on the basis of their correctly response to the first target stimulus (T1) was calculated to measure the $A B$ effect. The flight performance of these military pilots was also collected.

Results: The participants' accuracy in detecting T2/T1 at positions of 180, 270, 360, and 450 ms was significantly lower than that in detecting $T 1$ in both groups. The military pilots' detection accuracy of T2/T1 at the positions of $180 \mathrm{~ms}(p<0.001)$ and $270 \mathrm{~ms}$ $(p<0.001)$ was significantly higher than that of the control participants, and their mean detection accuracy of T2/T1 (AB effect) at the positions of 180, 270, 360, and $450 \mathrm{~ms}$ was also significantly higher than that of the control participants $(p<0.001)$. There was a significant correlation between the $\mathrm{AB}$ effect and the lowest flight performance score for the military pilots $(r=0.52, p=0.004)$, and the regression coefficient was significant $\left(\beta=0.514, p=0.004, R^{2}=0.31\right)$.

Conclusions: Both groups experienced the AB effect, but the military pilots' performance regarding the $A B$ effect was better than that of the control participants. The AB effect can predict the lowest flight performance score in military pilots. These findings may have implications for the grounding and selection of Chinese military pilots.

Keywords: military pilot, attentional blink, flight performance, cognitive ability, attention

\section{INTRODUCTION}

When multiple stimuli appear sequentially in the same location, if an individual detects the first target stimulus correctly, his or her accuracy in detecting a second target stimulus that appears within approximately $200-500 \mathrm{~ms}$ after the first target stimulus is low. This phenomenon is called attentional blink (AB; Raymond et al., 1992). It reflects attentional blindness in time. There are 
many theoretical explanations for $\mathrm{AB}$, such as inhibition theories (Dux and Marois, 2008), the temporary loss of control hypothesis (Di Lollo et al., 2005), and a two-stage model (Chun and Potter, 1995). In summary, there are two main theories (Dux and Marois, 2009). One of the main theories is that the emergence of $\mathrm{AB}$ is related to cognitive resources being limited. Individuals consume many cognitive resources when they detect the first target stimulus, so it very difficult for them to fully process the second target stimulus or allow the second target stimulus to be encoded into their working memory. The other main theory is that the $\mathrm{AB}$ effect is related to an individual's ability to suppress distraction stimuli. The number of distraction stimuli varies across target stimuli. It may be difficult for individuals to exclude them by cognitive control, resulting in a decline in their accuracy in detecting a second target stimulus.

The $\mathrm{AB}$ effect differs across various populations. Many studies have shown that the $\mathrm{AB}$ effect in social anxiety patients (Morrison et al., 2016), alcoholics (DePalma et al., 2017), autism patients (Amirault et al., 2009), and patients with schizophrenia (Mathis et al., 2011) are more severe. These populations generally have attention problems or executive cognitive defects, which prevent them from detecting target stimuli effectively. However, the AB performance of some athletes and players, such as shooting athletes (Mao, 2016), table tennis athletes and soccer players ( $\mathrm{Li}$, 2002; Li and Zhang, 2004), martial arts athletes (Liu, 2008), Sanda athletes (Wang and Zhou, 2010), and video game players (Green and Bavelier, 2003; Li et al., 2015), is better than that of ordinary people. This phenomenon might be attributed to their longterm experiences in training and playing games. Because of the intense, competitive environment, individuals must identify and judge rapidly changing information correctly by being attentive; otherwise, they lose the game.

As with high-performance athletes and video game players, pilots have to perform a difficult task that demands a large amount of attentional resources, i.e., flying a plane. In flight, military pilots need to monitor changes in the external environment and monitor the situation of the aircraft at the same time. Military pilots need to identify and filter many kinds of complex information immediately and correctly in a short period (Johnson et al., 2017). They must act appropriately, especially when they have to handle a variety of emergencies. Otherwise, accidents can easily occur in flight. Then, are military pilots' attentional abilities as high as those of high-performance athletes and video game players? Is military pilots' AB performance better than that of ordinary people? Additionally, detecting information correctly in a short period is a basic prerequisite for military pilots to avoid accidents in flight (O'Hare, 2006). Therefore, can the $\mathrm{AB}$ effect predict flight performance? There are few related studies about these questions. The aim of the present study was to investigate them.

\section{MATERIALS AND METHODS}

\section{Participants}

The present study mainly focused on males because the majority of military pilots are male. Thirty male military pilots and
29 male control participants participated in the study. The pilots were $44.23 \pm 4.07$ years old. Their flight times were $3402.10 \pm 1196.12 \mathrm{~h}$, and the types of aircrafts that they flew were fighters (63.3\%), trainers (20\%), bombers (10\%), and airfreighters $(6.7 \%)$. The control participants were $44.07 \pm 2.93$ years old and were administrative staff members of the Air Force. Each participant's visual acuity or corrected visual acuity was normal, without color vision deficiencies or color blindness. All participants were in good health, with no histories of major physical diseases or mental disorders.

\section{Design and Procedure}

The classic rapid serial visual presentation (RSVP) paradigm was adopted in the present study (Martens and Wyble, 2010); 10 stimuli, including several numbers and two letters, were displayed each second on a computer screen. The numbers were the distraction stimuli, while the letters were the target stimuli that the subjects were required to detect correctly. It is worth mentioning that to eliminate interference between numbers and letters, $0,1, \mathrm{I}, \mathrm{O}, \mathrm{Q}$ and $\mathrm{Z}$ were not included in the experiment. The background color of the computer screen was black. The colors of all the stimuli were white, the text font was Courier New, and the text size was 40 .

The RSVP paradigm included two blocks. The first block, i.e., the practice session, contained eight trials; the second block, i.e., the formal experiment, comprised 72 trials. The experimental design for each trial is shown in Figure 1. First, a fixation point (“+”) was presented on the computer screen for $1000 \mathrm{~ms}$. Then, a series of numbers and letters were continuously presented at the position of the fixation point. Two letters, which were the target stimuli, were displayed in each trial. Each number or letter shown on the computer screen was presented for $15 \mathrm{~ms}$. The interval between stimuli was $75 \mathrm{~ms}$. There were four to six numbers (the distraction stimuli) that were displayed before the first letter appeared (the first target stimulus, denoted as T1). Then, four to six numbers were displayed after the second letter appeared (the second target stimulus, denoted as T2). Between T1 and T2, there were various numbers of distraction stimuli, ranging from zero to seven. In other words, T2 appeared in the first to the eighth

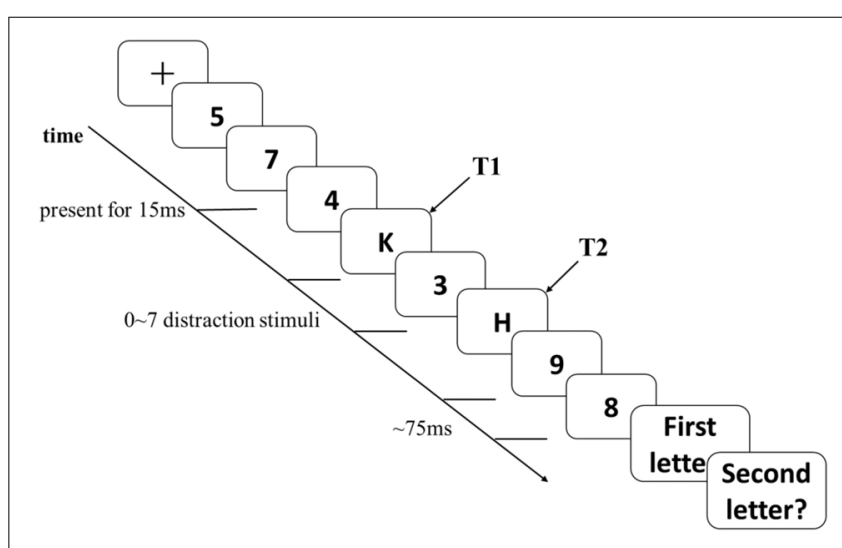

FIGURE 1 | The classic rapid serial visual presentation paradigm. 
position after T1. All the letters and numbers appeared randomly. The entire experimental procedure was implemented in E-Prime Studio 3.0 on 14-inch, $1920 \times 1080$ HD LED ThinkPad monitors at a $60 \mathrm{~Hz}$ refresh rate.

Primarily, the participants were asked to sign an informed consent form and fill out a basic information questionnaire. The pilot's basic information included sex, age, flight time, and flight performance. The pilots' flight performance, such as his accuracy in performing special flight maneuvers and flight course, was assessed by the supervisor twice a year according to the Flight Assessment Outline established by the Chinese Air Force. The pilots received one comprehensive score based on the internal scoring system after each flight assessment. In the present study, flight performance included the highest, average, and lowest scores over the past 5 years. The control participants' basic information included sex and age. Then, both groups underwent testing with the RSVP paradigm. During the experimental session, the participants were approximately $50 \mathrm{~cm}$ away from the computer screen, which was a comfortable distance for them.

The participants needed to immediately identify the two target stimuli after each trial was presented and type them into the computer in order. The present study mainly investigated participants' accuracy in detecting T2 on the basis of a correct response to $\mathrm{T} 1$ (T2/T1). If $\mathrm{T} 2$ appeared immediately after $\mathrm{T} 1$, there was no distraction stimulus between $\mathrm{T} 1$ and $\mathrm{T} 2$, and the accuracy in detecting T2/T1 was recorded as lag1 (90 ms). If there was a distraction stimulus between $\mathrm{T} 1$ and $\mathrm{T} 2$, then the accuracy of $\mathrm{T} 2 / \mathrm{T} 1$ was recorded as lag2 (180 ms). If there were two distraction stimuli between $\mathrm{T} 1$ and $\mathrm{T} 2$, then the accuracy of T2/T1 was recorded as lag3 (270 ms). The remaining data were recorded in the same manner until lag 8 $(720 \mathrm{~ms})$, which means that there were 7 distraction stimuli between $\mathrm{T} 1$ and $\mathrm{T} 2$.

\section{Statistical Analysis}

Data processing and statistical analyses were conducted in SPSS 22.0. ANOVA, correlation analysis and regression analysis were conducted in the present study.

\section{RESULTS}

\section{Attentional Blink Effects Were Observed in Both Groups}

To examine whether the military pilots experienced an $A B$ effect, their accuracy in detecting the target stimuli (the overall accuracy for $\mathrm{T} 1$ and the accuracy for T2/T1 at each position) was analyzed by one-way repeated measures ANOVA (positions: T1 vs lag1 vs lag 2 vs lag3 vs lag4 vs lag5 vs lag6 vs lag7 vs lag8). The results showed that the main effect of position was significant $\left(F=8.84, p<0.001, m \eta^{2}=0.76\right)$. The results of the post hoc test, where the overall accuracy of T1 was used as the baseline level for comparison, showed that the accuracy values for only lag2 $(180 \mathrm{~ms}), \operatorname{lag} 3(270 \mathrm{~ms}), \operatorname{lag} 4(360 \mathrm{~ms})$, and lag5 $(450 \mathrm{~ms})$ were significantly lower than the overall accuracy for T1 (Table 1). Similarly, one-way repeated measures ANOVA with position
TABLE 1 | Results of the post hoc tests in which the overall accuracy for T1 was used as the baseline level for comparison.

\begin{tabular}{|c|c|c|c|c|}
\hline \multirow[t]{2}{*}{$\mathrm{T} 1$ - $\mathrm{T} 2 / \mathrm{T} 1$} & \multicolumn{2}{|c|}{ Military pilots } & \multicolumn{2}{|c|}{ Control participants } \\
\hline & $M_{\mathrm{T} 1-\mathrm{T} 2 / \mathrm{T} 1}$ & SD & $M_{\mathrm{T} 1-\mathrm{T} 2 / \mathrm{T} 1}$ & SD \\
\hline T1-lag1 & 0.01 & 0.02 & 0.05 & 0.02 \\
\hline T1-lag2 & $0.19^{\star \star}$ & 0.03 & $0.36^{\star \star}$ & 0.03 \\
\hline T1-lag3 & $0.12^{\star \star}$ & 0.03 & $0.28^{\star \star}$ & 0.03 \\
\hline T1-lag4 & $0.06^{\star \star}$ & 0.02 & $0.08^{\star \star}$ & 0.02 \\
\hline T1-lag5 & $0.04^{*}$ & 0.02 & $0.04^{\star}$ & 0.02 \\
\hline T1-lag6 & -0.02 & 0.01 & 0.03 & 0.02 \\
\hline T1-lag7 & -0.03 & 0.01 & 0.00 & 0.01 \\
\hline T1-lag8 & 0.02 & 0.02 & 0.04 & 0.03 \\
\hline
\end{tabular}

${ }^{*} p<0.05,{ }^{* *} p<0.01$. T1 was the participants' overall accuracy in detecting the first target stimulus, and T2/T1 was their accuracy in detecting the second target stimulus. lag1 was the accuracy for T2/T1 at the position of 90 ms, and lag2 was the accuracy for T2/T1 at the position of $180 \mathrm{~ms}$. lag4 lag8 were recorded in the same manner.

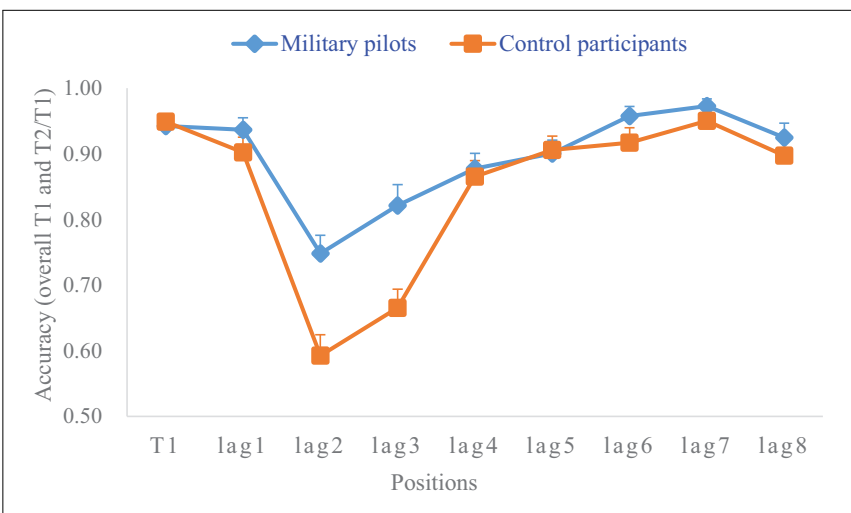

FIGURE 2 | A line chart showing the accuracy for both groups.

as a within-subject factor was also conducted on the control groups. The results showed that the main effect of position was significant $\left(F=30.57, p<0.001, \mathrm{~m}^{2}=0.92\right)$, and the results of the post hoc test also showed that the accuracy values for only lag2 (180 ms), lag3 (270 ms), lag4 (360 ms), and lag5 (450 ms) were significantly lower than the overall accuracy for T1 (Table 1). Both lines on the chart had a "U" shape (Figure 2). These results indicated that both groups experienced an $\mathrm{AB}$ effect during 180-450 ms.

Therefore, the present study considered the mean accuracy values for lag2, lag3, lag4, and lag5 as measures of the $\mathrm{AB}$ effect. The formula used to calculate this measure was $\mathrm{AB}=(\operatorname{lag} 2+\operatorname{lag} 3+\operatorname{lag} 4+\operatorname{lag} 5) / 4$. The larger the $\mathrm{AB}$ value was, the better the performance regarding the $\mathrm{AB}$ effect was.

\section{The AB Performance of the Military Pilots Was Better Than That of the Control Participants}

To compare the $\mathrm{AB}$ performance between the two groups, the overall accuracy of $\mathrm{T} 1$ and $\mathrm{T} 2 / \mathrm{T} 1$ at each position and the $\mathrm{AB}$ value are shown in Table 2 . $\mathrm{Li}$ (2002) proposed that if the accuracy 
TABLE 2 | The analysis of the simple effects.

\begin{tabular}{lcccc}
\hline & $\boldsymbol{M}_{\text {pilots }}$ & $\boldsymbol{M}_{\text {control }}$ & SD & SD \\
\hline T1 & 0.94 & 0.95 & -0.01 & 0.01 \\
lag1 & 0.94 & 0.90 & 0.04 & 0.03 \\
lag2 & 0.75 & 0.59 & $0.16^{\star \star \star}$ & 0.04 \\
lag3 & 0.82 & 0.67 & $0.15^{\star \star *}$ & 0.04 \\
lag4 & 0.88 & 0.87 & 0.01 & 0.03 \\
lag5 & 0.90 & 0.91 & -0.01 & 0.03 \\
lag6 & 0.96 & 0.92 & 0.04 & 0.03 \\
lag7 & 0.97 & 0.95 & 0.02 & 0.02 \\
lag8 & 0.92 & 0.91 & 0.01 & 0.03 \\
AB & 0.84 & 0.76 & $0.08^{* \star *}$ & 0.02 \\
\hline$* * p<0.001$. & & & &
\end{tabular}

for $\mathrm{T} 2 / \mathrm{T} 1$ was greater than $95 \%$, there was no $\mathrm{AB}$ effect. If it was between 85 and 95\%, there was a slight $A B$ effect. If it was $75-85 \%$, there was a mild $A B$ effect. If it was $65-75 \%$, there was a moderate $A B$ effect. If it was 55-65\%, there was a severe $A B$ effect. If it was lower than 55\%, there was a complete $\mathrm{AB}$ effect. According to this classification, the results in Table 2 show that the military pilots experienced stages of slight and mild $\mathrm{AB}$ successively, and the control participants experienced stages of severe, moderate and mild AB successively.

More specifically, the overall accuracy for T1 and T2/T1 at each position and the $\mathrm{AB}$ value were examined with $2 \times 10$ (groups: pilots vs control) (T1 vs lag1 vs lag2 vs lag3 vs lag4 vs lag5 vs lag6 vs lag7 vs lag8 vs $A B$ ) mixed-design ANOVA, with group as a between-subjects factor. The results showed that the main effect of the between-subjects factor was significant $\left(F=36.52, p<0.001, m \eta^{2}=0.85\right)$, and the interaction effect was also significant $\left(F=4.77, p<0.001, m \eta^{2}=0.43\right)$. Then, the analysis of the simple effect showed that there was no significant difference between the two groups in the overall accuracy for T1 (Table 2), indicating that they had the same baseline level. However, the lag2 and lag3 values for the military pilots were significantly higher than those for control participants, and the pilots' $\mathrm{AB}$ performance was also significantly higher than that of the control participants (Table 2). These results indicated that the $\mathrm{AB}$ performance of military pilots is better than that of the control participants.

\section{The Relationship Between the AB Effect and Flight Performance}

Partial correlation analysis was conducted between $\mathrm{AB}$ and flight performance, with age and flight time serving as control variables. The AB effect was significantly correlated with the lowest score $(r=0.52, p=0.004$; Figure 3$)$ but not with the highest $(r=-$ $0.09, p=0.65$; Figure 4) and average scores $(r=0.18, p=0.36$; Figure 5). This finding indicated that better $A B$ performance was associated with the lowest flight performance score.

Then, a regression analysis was conducted, with the $A B$ effect as the predictive variable and the lowest score as the dependent variable. When age and flight time were considered control variables, the regression effect was significant, with a standardized regressive coefficient of $\beta=0.514$ ( $p=0.004$

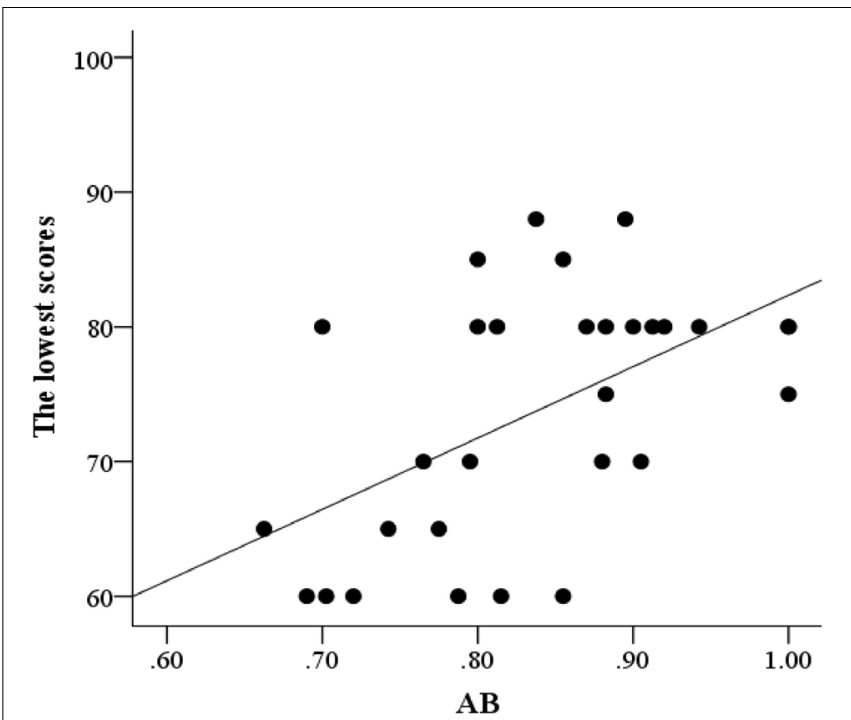

FIGURE 3 | A scatter plot of the relationship between $A B$ and the lowest flight performance scores.

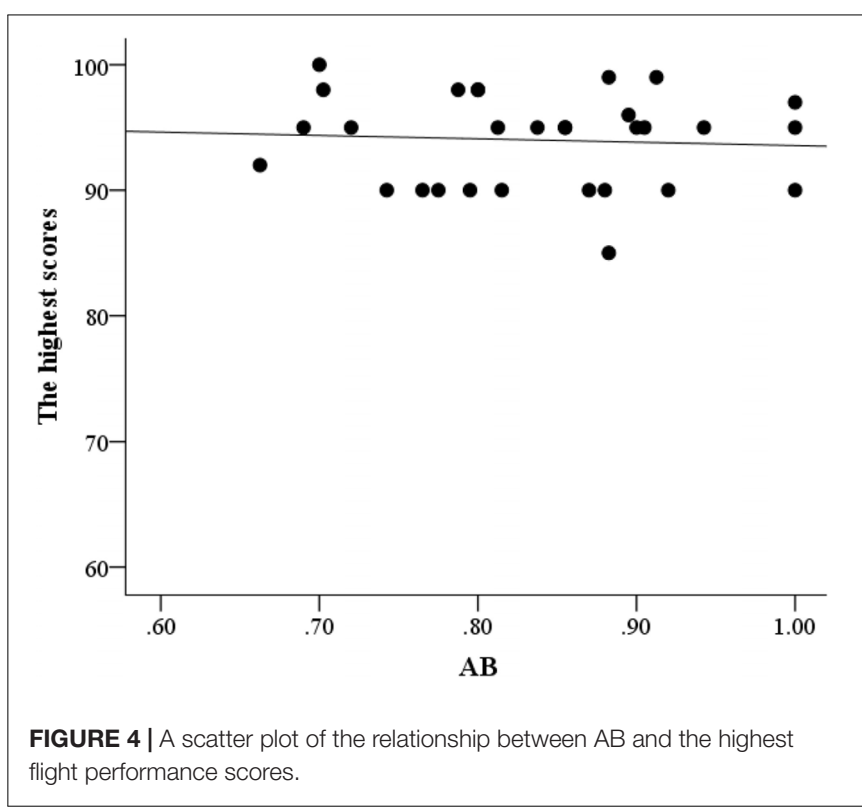

and $R^{2}=0.31$ ) (Table 3 ). This finding indicated that the $\mathrm{AB}$ effect of military pilots can significantly predict the lowest flight performance score.

\section{DISCUSSION}

Attention is the basis of human information processing. The $\mathrm{AB}$ effect suggests that when people correctly identify some information, their ability to accurately identify subsequent stimuli is affected. Raymond et al. (1992) found that if subjects detect the first target stimulus correctly, the distribution diagram of their accuracy in detecting a second target stimulus forms 


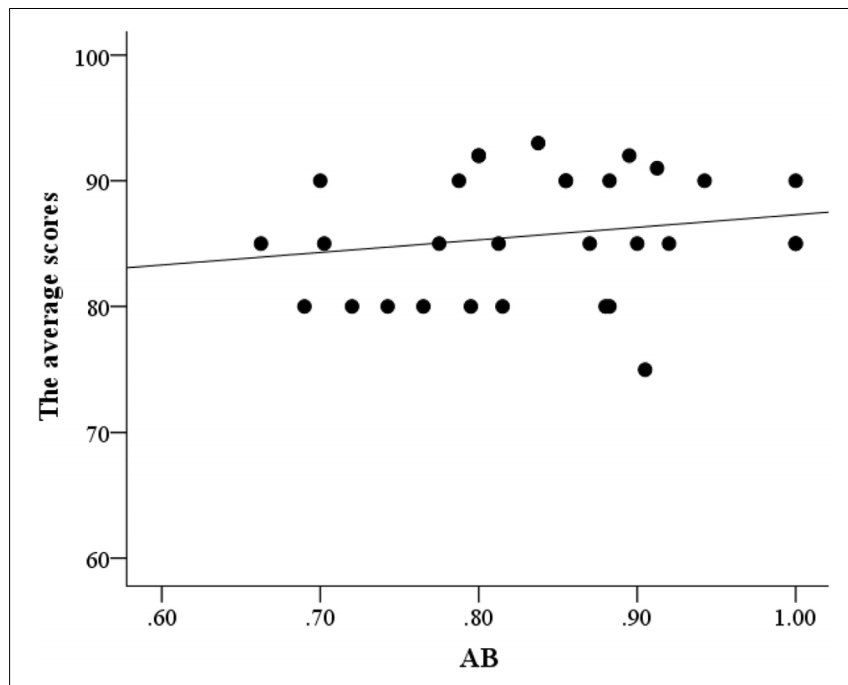

FIGURE 5 | A scatter plot of the relationship between $A B$ and the average flight performance scores.

TABLE 3 | Regression analysis of AB and the lowest flight performance score.

\begin{tabular}{|c|c|c|c|c|c|}
\hline & \multirow[t]{2}{*}{$\beta$} & \multirow[t]{2}{*}{$t$} & \multirow[t]{2}{*}{$p$} & \multicolumn{2}{|c|}{$95 \% \mathrm{Cl}$ of $\mathrm{B}$} \\
\hline & & & & Lower bound & Upper bound \\
\hline Constant & & 2.004 & 0.056 & -1.210 & 95.931 \\
\hline Age & -0.167 & -0.813 & 0.424 & -1.345 & 0.583 \\
\hline Flight time & 0.005 & 0.025 & 0.981 & -0.003 & 0.003 \\
\hline$A B$ & $0.514^{\star *}$ & 3.132 & 0.004 & 17.693 & 85.247 \\
\hline
\end{tabular}

a "U" shape. In other words, the correct detection of the first stimulus has a negative influence on individuals' accuracy in detecting the second target stimulus. This finding has been reported in a large number of studies (Popple and Levi, 2007; MacLean and Arnell, 2012; Dale et al., 2013), and it seems to be a phenomenon that is difficult to avoid. The present study supports these findings as well. In the present study, both groups experienced the $\mathrm{AB}$ effect.

However, the military pilot's $A B$ performance was better than that of the control group, and the $\mathrm{AB}$ effect could predict the lowest flight performance score among the military pilots. Theoretically, the $\mathrm{AB}$ effect may reflect an individual's working memory and his or her ability to suppress distraction stimuli, both of which are essential for military pilots (Martins, 2016). As complex advancements in the airplane cockpit have been made to provide more information and make it more intelligent, the information provided by the display and control system has also become diverse and complex. A variety of information is available to provide military pilots with comprehensive and accurate data about airplane cockpit conditions and the external environment (Cheng et al., 2019). However, these advancements lead to a new problem; some key information may be hidden or overlooked accidently among the large amount of display information. It is therefore difficult for military pilots to select and perceive the information accurately (O'Hare, 2006), which can result in some human errors and catastrophic consequences in practice. Therefore, military pilots need to monitor internal and external environmental information in real time with their working memory and inhibition abilities. They need to identify and judge the conditions of instruments immediately (Wu et al., 2015). They must collect and integrate all types of information to make appropriate decisions while dismissing distraction stimuli ( $Y u$ et al., 2016). In short, good $A B$ performance among military pilots ensures that they are able to obtain as much information as possible and reduces the probability that they will miss important information. Without a doubt, this phenomenon may be related to their long-term flight training and experience.

The result in this study showing that $\mathrm{AB}$ can predict flight performance is consistent with previous findings, which indicates that $\mathrm{AB}$ can predict the driving performance (Trick et al., 2008) and flight performance (Du et al., 2015). Nevertheless, it is interesting to note that the present study showed that the $A B$ effect has a significant correlation with the lowest score but not the highest and average scores of flight performance. In other words, the lowest flight performance scores can be predicted by the military pilot's $A B$ effect. This finding indicates that the $\mathrm{AB}$ effect is not limited to being a measure of military pilots' competency, but it may be one of the objective indicators for predicting possible accidents in flight. Xing and Bailey (2005) found that $60 \%$ of flight operation errors were related to attention and memory, and the $\mathrm{AB}$ effect was one of the three major reasons. The more serious the $\mathrm{AB}$ effect is, the more likely that an accident will occur. After all, when pilots do not miss any information during flight, especially key information, flight safety is guaranteed.

Therefore, the results of the present study suggest there is an objective indicator to determine whether military pilots need to be grounded. At present, there are three major reasons for Chinese military pilots need to be grounded. The first reason is physical illness, such as problems with the eyes and spine (Wang and Zhan, 2019). The second reason is related to psychological factors, such as mental health (Qi et al., 2019), emotion (Lin and Zhang, 2001), personality (Yi and Huang, 2011), and spatial disorientation (Zhang, 2011). The last reason is related to age. For example, according to the latest version of Provisions on Administration of Flight Personnel, military pilots who are in a certain age range are considered for grounding. However, it may be controversial to ground for some pilots who are at the lower limit of the age range. In addition, more information other than age may be needed. For example, individuals' cognitive performance needs to be examined after physical and psychological problems are excluded. For instance, some pilots may be younger than a certain age, but their $\mathrm{AB}$ performance has declined. If they continue to fly a plane, the number of flight errors that occur might increase. Conversely, other pilots may be older than a certain age, but they are in good condition, and their $\mathrm{AB}$ performance is still good, indicating that they are able to continue flying. If they are grounded, it may be a waste of manpower. Therefore, the $\mathrm{AB}$ effect can be used as an indicator for military pilots to be grounded to prevent 
the occurrence of flight accidents and improve the selection of pilots for grounding.

In addition, it may also be beneficial for the selection of military pilots to use the $\mathrm{AB}$ effect as one criterion. The cost of training a military pilot is very high (Li, 1983; Fu, 2000). It takes at least 6-8 years to become a qualified pilot from a flying cadet. Therefore, it may be that some cadets who have poor AB performance should not be recruited. It will take more time, effort, and financial resources to train them to fly planes safely. If we put effort and financial resources into training the potential cadets and exclude those who cannot suppress distraction stimuli or are likely to miss key information, training efficiency will greatly improve. However, these assumptions need to be further verified by longitudinal studies in the future.

\section{CONCLUSION}

In conclusion, the present study showed that both military pilots and ordinary people experience the $\mathrm{AB}$ effect. However, the military pilot's $\mathrm{AB}$ performance was better than that of the control participants, and the $\mathrm{AB}$ effect can predict the lowest flight performance among military pilots. These findings may have implications for the grounding and selection of Chinese military pilots.

\section{REFERENCES}

Amirault, M., Delord, S., Mendizabal, S., Kraushaar, C., Hesling, I., Allard, M., et al. (2009). Alteration of attentional blink in high functioning autism: a pilot study. J. Autism. Dev. Disord. 3, 1522-1528. doi: 10.1007/s10803-009-0821-5

Cheng, N., Wu, H., and Qiu, Z. (2019). Modeling interaction between pilot and airborne computer and research on its problems. Aeronaut. Comput. Tech. 49, 105-108.

Chun, M. M., and Potter, M. C. (1995). A two-stage model for multiple target detection in rapid serial visual presentation. J. Exp. Psychol. Hum. Percept. Perform. 21, 109-127. doi: 10.1037/0096-1523.21.1.109

Dale, G., Dux, P. E., and Arnell, K. M. (2013). Individual differences within and across attentional blink tasks revisited. Attent. Percept. Psychophys. 75, 456-467. doi: 10.3758/s13414-012-0415-8

DePalma, F. M., Ceballos, N., and Graham, R. (2017). Attentional blink to alcohol cues in binge drinkers versus non-binge drinkers. Addict. Behav. 73, 67-73. doi: 10.1016/j.addbeh.2017.04.020

Di Lollo, V., Kawahara, J., Ghorashi, S. M. S., and Enns, J. T. (2005). The attentional blink: resource depletion or temporary loss of control? Psychol. Res. 69, 191-200. doi: 10.1007/s00426-004-0173-x

Du, F., Zhang, J., and Dai, M. (2015). "Attentional switch characteristics are correlated with the performance of simulated aviation task," in Proceedings fo International Conference on Human-Computer Interaction, (Cham: Springer).

Dux, P. E., and Marois, R. (2008). Distractor inhibition predicts individual differences in the Attentional Blink. PLoS One 3:e3330. doi: 10.1371/journal. pone. 0003330

Dux, P. E., and Marois, R. (2009). The attentional blink: a review of data and theory. Attent. Percept. Psychophys. 71, 1683-1700. doi: 10.3758/app.71.8.1683

Fu, S. (2000). Measuring system for pilots' psychological selection. China Sci. Technol. Resour. Rev. 7, 23-26.

Green, C. S., and Bavelier, D. (2003). Action video game modifies visual selective attention. Nature 423, 534-537. doi: 10.1038/nature01647

Johnson, J. F., Barron, L. G., Carretta, T. R., and Rose, M. R. (2017). Predictive validity of spatial ability and perceptual speed tests for aviator training. Int. J. Aerospace Psychol. 27, 109-120. doi: 10.1080/24721840.2018.1442222

Li, L. (1983). The selection of military pilots. Psychol. Sci. 6, 299-304.

\section{DATA AVAILABILITY STATEMENT}

All datasets presented in this study are included in the article/supplementary material.

\section{ETHICS STATEMENT}

The studies involving human participants were reviewed and approved by First Affiliated Hospital of Air Force Medical University. The patients/participants provided their written informed consent to participate in this study.

\section{AUTHOR CONTRIBUTIONS}

FL conceived the study and wrote the manuscript. XZ, QL, and HL critically reviewed the drafts of the manuscript. All authors contributed to the article and approved the submitted version.

\section{FUNDING}

This work was supported by the Major Project of Medicine Science and Technology of PLA (Grant No.AWS17J012).

Li, R. W., Ngo, C. V., and Levi, D. M. (2015). Relieving the attentional blink in the amblyopic brain with video games. Sci. Rep. 5:8483.

Li, Y. (2002). Preliminary research on characteristics of attentional blink in high-level athletes of different attention type. J. Beijing Univ. Phys. Educ. 25, 43-46.

Li, Y., and Zhang, H. (2004). Experimental Study on the characteristics of female soccer players' attentional blink. J. Beijing Sport Univ. 27, 1193-1195.

Lin, Y., and Zhang, D. (2001). The important emotional disorder leading to grounding-excessive tension and anxiety. J. China Civil Aviat. Flying Coll. 12, 24-26.

Liu, J. (2008). Study on the characteristics of attention blink of female taekwondo athletes. China Sport Sci. Technol. 42, 60-64.

MacLean, M. H., and Arnell, K. M. (2012). A conceptual and methodological framework for measuring and modulating the attentional blink. Attent. Percept. Psychophys. 74, 1080-1097. doi: 10.3758/s13414-012-0338-4

Mao, H. (2016). Research on the Influence of Attention Fatigue and Anxiety to Attentional Blink in Shooting Athletes and Its' Applying. Unpublished Master Thesis, Henan University, Kaifeng.

Martens, S., and Wyble, B. (2010). The attentional blink: past, present, and future of a blind spot in perceptual awareness. Neurosci. Biobehav. Rev. 34, 947-957. doi: 10.1016/j.neubiorev.2009.12.005

Martins, A. P. G. (2016). A review of important cognitive concepts in aviation. Aviation 20, 65-84. doi: 10.3846/16487788.2016.1196559

Mathis, K. I., Wynn, J. K., Breitmeyer, B., Nuechterlein, K. H., and Green, M. F. (2011). The attentional blink in schizophrenia: isolating the perception/attention interface. J. Psychiatr. Res. 45, 1346-1351. doi: 10.1016/ j.jpsychires.2011.04.002

Morrison, A. S., Brozovich, F. A., Lakhan-Pal, S., Jazaieri, H., Goldin, P. R., Heimberg, R. G., et al. (2016). Attentional blink impairment in social anxiety disorder: depression comorbidity matters. J. Behav. Ther. Exp. Psychiatry 50, 209-214. doi: 10.1016/j.jbtep.2015.08.006

O'Hare, D. (2006). Cognitive functions and performance shaping factors in aviation accidents and incidents. Int. J. Aviat. Psychol. 16, 145-156. doi: 10. 1207/s15327108ijap1602_2

Popple, A. V., and Levi, D. M. (2007). Attentional blinks as errors in temporal binding. Vis. Res. 47, 2973-2981. doi: 10.1016/j.visres.2007.06.022 
Qi, J., Yu, D., Liu, J., and Wang, J. (2019). Aviation medical identification and clinical analysis of depression disorders in grounded military aircrew from 2004 to 2016. Med. J. Air Force 35, 467-469.

Raymond, J. E., Shapiro, K. L., and Arnell, K. M. (1992). Temporary suppression of visual processing in an RSVP task: an attentional blink? J. Exp. Psychol. 18, 849-860. doi: 10.1037/0096-1523.18.3.849

Trick, L., Brandigampola, S., and Enns, J. (2008). Does the prolonged attentional blink to emotional stimuli affect driving performance? J. Vis. 8:15. doi: 10.1167/ 8.6.15

Wang, X., and Zhan, S. (2019). Meta-analysis of disease spectrum associated with flying disqualification of Chinese military pilots. Med. J. Air Force 35, 293-296.

Wang, X., and Zhou, C. (2010). Research on attentional blink character and neural mechanism of female sanda athlete. China Sport Sci. Technol. 46, 76-78.

Wu, Q., Zhang, X., Qin, Z., Wang, Z., and Ma, Y. (2015). Human agility: a new requirement to modern fighter aircraft pilot. Chin. J. Aerospace Med 26, $161-166$.

Xing, J., and Bailey, L. L. (2005). Attention and memory in air traffic control tasks. J. Vis. 5, 427. doi: 10.1167/5.8.427
Yi, S., and Huang, D. (2011). Analysis of the test results of personality characteristics in flying college students. J. Aerospace Med. 22, 947-948.

Yu, C., Wang, E. M., Li, W., Braithwaite, G., and Greaves, M. (2016). Pilots' visual scan patterns and attention distribution during the pursuit of a dynamic target. Aerospace Med. Hum. Perform. 87, 40-47. doi: 10.3357/amhp.4209.2016

Zhang, T. (2011). Research on the Evaluation of Military Pilots' Brain Image Under Stress. Unpublished Master Thesis, Fourth Military Medical University, Xi'an.

Conflict of Interest: The authors declare that the research was conducted in the absence of any commercial or financial relationships that could be construed as a potential conflict of interest.

Copyright (C) $2020 \mathrm{Li}, \mathrm{Liu}, \mathrm{Lu}$ and Zhu. This is an open-access article distributed under the terms of the Creative Commons Attribution License (CC BY). The use, distribution or reproduction in other forums is permitted, provided the original author(s) and the copyright owner(s) are credited and that the original publication in this journal is cited, in accordance with accepted academic practice. No use, distribution or reproduction is permitted which does not comply with these terms. 